\title{
The Therapeutic Effects of Bevacizumab in Patients with Polypoidal Choroidal Vasculopathy
}

\author{
Sun Young Lee, MD, June-Gone Kim, MD, Soo Geun Joe, MD, \\ Hyewon Chung, MD, Young Hee Yoon, MD \\ Department of Ophthalmology, Asan Medical Center, University of Ulsan, College of Medicine, Seoul, Korea
}

\begin{abstract}
Purpose: To evaluate the efficacy and safety of intravitreal bevacizumab for polypoidal choroidal vasculopathy (PCV).

Methods: In this retrospective interventional pilot study, 12 eyes of 11 patients with active PCV were treated with intravitreal bevacizumab $(1.25 \mathrm{mg})$ alone or in combination with photodynamic therapy (PDT) depending on the informed patient's choice. Intravitreal bevacizumab was repeated at 6-week intervals until the regression of active lesion was detected on fluorescein angiography (FA) which was done on a regular basis, Indocyanine green angiography (ICGA) and optical coherence tomography (OCT) analyses.

Results: Intravitreal bevacizumab was given alone in 8 eyes (Group 1) and in combination with PDT in 4 eyes (Group 2). Mean follow-up duration was 17 weeks in group 1 and 15 weeks in group 2 after bevacizumab treatment. The mean number of bevacizumab injections was 2.2 in group 1 and 2.5 in group 2. Mean BCVA improved from $20 / 63$ to $20 / 40$ in group 1 and $20 / 63$ to $20 / 32$ in group 2 . Of all eyes, the BCVA improved by $\geq 2$ lines in seven $(58 \%)$ eyes and resolution of fluid and hemorrhages in clinical examination, an absence of leakage on repeat FAs, or resolved pigment epithelial detachment (PED) and/or subretinal fluid (SRF) on OCT exam was confirmed in 10 (83\%) eyes. Partial or complete regression of the polypoidal vessels and interconnecting vessels was reported for most cases at the last follow-up. No significant ocular or systemic side effects were observed in both groups.

Conclusions: Short-term results indicate that intravitreal bevacizumab $(1.25 \mathrm{mg})$ alone or in combination with PDT is well tolerated and associated with improvement in BCVA and reduced angiographic leakage in most patients. Further evaluation of intravitreal bevacizumab therapy for the treatment of PCV is warranted.
\end{abstract}

Korean Journal of Ophthalmology 22(2):92-99, 2008

Key Words: Intravitreal bevacizumab, Polypoidal choroidal vasculopathy, Photodynamic therapy

Polypoidal choroidal vasculopathy (PCV) is a choroidal vascular disease characterized by an inner choroidal vascular network ending in an aneurysmal bulge or outward projection visible clinically as a reddish orange, spheroid, polyp-like structure. $^{1-3}$

PCV can remain clinically asymptomatic in its quiescent form, with nonleaking asymptomatic polyps. Occasionally, PCV causes insidious visual loss owing to serosanguinous detachment of the retinal pigment epithelium and neurosensory retina affecting the macula, or causes acute and

Received: September 6, $2007 \quad$ Accepted: April 10, 2008

Reprint requests to Young Hee Yoon, MD, PhD, Department of Ophthalmology, University of Ulsan, Asan Medical Center, 388-1, Poongnap-dong, Songpa-gu, Seoul 138-040, Korea. Fax: 82-02-4706440, Tel: 82-02-3010-3675, E-mail: yhyoon@amc.seoul.kr

* This study was partially supported by Asan Institute for Life \& Science Grant \# 07-084 Competing interests: We declare that we have no conflicting financial interests. severe visual loss secondary to massive submacular or vitreous hemorrhage due to spontaneously ruptured vessels. ${ }^{4,5}$ Treatment for PCV is not yet well established. Asymptomatic PCV is recommended for observation and the polyps may resolve spontaneously over time., Although various treatment modalities for PCV with exudative and hemorrhagic complications such as direct thermal laser photocoagulation, tissue plasminogen activator ( $\mathrm{t}-\mathrm{PA})$ injection with gas displacement, submacular surgery, and macular translocation surgery have been proposed, the beneficial effects are still in doubt owing to recurrence or poor long-term results. ${ }^{7-11}$ Recently, photodynamic therapy (PDT) has been proposed as a standard treatment modality with its favorable outcome, nevertheless its application has been found to be limited owing to difficulty in treating all wide spread multiple polyps and the possibility of subsequent massive submacular hemorrhage. ${ }^{12-14}$

Favorable results have been reported with intravitreal injection of bevacizumab (Avastin ${ }^{\mathbb{B}}$, Genentech, Inc. South San Francisco, CA) to treat choroidal neovascularization. ${ }^{15-18}$ 
Although the pathogenesis of PCV is still not fully understood, it has been suggested that vascular endothelial growth factor (VEGF) may have a similar role in PCV as it does in choroidal neovascularization (CNV) owing to marked increases in VEGF concentration in aqueous humor and histologic examination in active PCV eyes. ${ }^{19,20}$ The aim of the present study was to determine the efficacy and safety of intravitreal bevacizumab, alone or in combination with PDT, for the treatment of PCV.

\section{Materials and Methods}

The retrospective interventional case series study included medical records of 12 eyes of 11 patients with symptomatic PCV who were either newly diagnosed or failed in previous treatment and treated PCV at Asan Medical Center, Seoul, Korea, from January 2006 to October 2006. The study was approved by the Institutional Review Board at the Asan Medical Center and informed consent was obtained from all patients. Patients with new or recurrent subretinal pigment epithelial orange-red vascular lesions associated with exudative changes were included. To confirm the diagnosis of symptomatic PCV, all patients underwent fluorescein angiography (FA), indocyanine green angiography (ICGA), and optical coherence tomography (OCT) analyses. All patients also underwent a comprehensive ocular examination, including best-corrected visual acuity (BCVA), slit-lamp biomicroscopy with intraocular pressure measurement and indirect ophthalmoscopy.

Patients received either an intravitreal injection of bevacizumab alone (Group 1) or an intravitreal injection of bevacizumab combined with PDT on the same day (Group 2) according to informed patient's choice. For intravitreal injection, $1.25 \mathrm{mg}$ of bevacizumab was given using a $30-$ gauage needle after topical anesthesia. For combination therapy, PDT was performed to cover the entire lesion of symptomatic PCV lesions in a standard manner and the $1.25 \mathrm{mg}$ intravitreal bevacizumab injection was then administered.

Follow-up evaluations were made at 1 week, 6 weeks and then every 2-3 months after treatment. BCVA, funduscopic exam, and OCT tests were performed at every visit, and FA/ICGA was assessed at the $\sim 3$ month visit or earlier if necessary. FA/ICGA findings were reviewed to confirm the regression of active PCV, and visual acuity and tomographic findings were recorded to assess the efficacy of the treatment. Side effects related to the procedure were also evaluated.

\section{Results}

The patient characteristics and clinical data of group 1 and group 2 are listed in Table 1 and Table 2. The 11 patients (ten men and one woman) were aged $45-80$ years (mean $63 \pm 7$ years in group 1 and $53 \pm 7$ years in group 2). Cases 1 and 8 in group 1 and case 9 in group 2 received prior PDT (9, 4, and 22 months before treatment of bevacizumab,

Table 1. Clinical Data and Treatment Results in Patients with Polypoidal Choroidal Vasculopathy Treated by Intravitreal Bevacizumab (Group 1)

\begin{tabular}{|c|c|c|c|c|c|c|c|c|c|c|}
\hline $\begin{array}{l}\text { PatientNo./ } \\
\text { Gender/ } \\
\text { Age (years) }\end{array}$ & Location & $\begin{array}{l}\text { Prior } \\
\mathrm{Tx}\end{array}$ & Treatment* & $\begin{array}{l}\text { BCVA } \\
\text { Pre** }\end{array}$ & $\begin{array}{l}\text { BCVA } \\
\text { Final }\end{array}$ & $\begin{array}{l}\text { Change } \\
\text { in lines }\end{array}$ & $\begin{array}{l}\text { Duration } \\
\text { of } \mathrm{F} / \mathrm{U}^{\dagger} \\
\text { (week) }\end{array}$ & $\begin{array}{l}\text { Clinical and } \\
\text { angiographic } \\
\text { features at } \\
\text { last F/U }\end{array}$ & $\begin{array}{l}\mathrm{OCT} \\
\text { features } \\
\text { at last } \mathrm{F} / \mathrm{U}\end{array}$ & $\begin{array}{l}\text { Additional } \\
\text { event }\end{array}$ \\
\hline $1 / \mathrm{M} / 66$ & Subfoveal & $P(-36)$ & $\mathrm{A}(0), \mathrm{A}(6), \mathrm{A}(12)$ & $20 / 100$ & $20 / 160$ & -2 & 17 & $\begin{array}{l}\text { Dry and } \\
\text { quiescent }\end{array}$ & $\begin{array}{l}\text { Resolved } \\
\text { PED }\end{array}$ & \\
\hline $2 / \mathrm{M} / 80$ & Juxtafoveal & & $\mathrm{A}(0), \mathrm{A}(6), \mathrm{A}(12)$ & $20 / 50$ & $20 / 32$ & +2 & 13 & $\begin{array}{l}\text { Dry and } \\
\text { quiescent }\end{array}$ & $\begin{array}{l}\text { Reduced PED } \\
\text { and SRF }\end{array}$ & \\
\hline $3 / \mathrm{M} / 63$ & Subfoveal & & $\mathrm{A}(0), \mathrm{A}(6), \mathrm{A}(12)$ & $20 / 63$ & $20 / 32$ & +3 & 17 & $\begin{array}{l}\text { Dry and } \\
\text { quiescent }\end{array}$ & Resolved SRF & \\
\hline 4/M/63 & Subfoveal & $\begin{array}{l}\mathrm{P}(-6), \\
\mathrm{T} / \mathrm{G}\end{array}$ & $\mathrm{A}(0), \mathrm{A}(6)$ & $20 / 200$ & $20 / 320$ & -2 & 12 & $\begin{array}{l}\text { Dry and } \\
\text { scarring }\end{array}$ & $\begin{array}{l}\text { Resolved PED } \\
\text { and RPE } \\
\text { scarring }\end{array}$ & $\begin{array}{l}\text { Massive } \\
\text { subretinal } \\
\text { hemorrhage } \\
\text { after PDT }\end{array}$ \\
\hline $5 / \mathrm{M} / 57$ & Extrafoveal & & $\mathrm{A}(0)$ & $20 / 25$ & $20 / 25$ & 0 & 22 & $\begin{array}{l}\text { Dry and } \\
\text { quiescent }\end{array}$ & Resolved PED & \\
\hline $6 / \mathrm{M} / 58$ & Juxtafoveal & & $\mathrm{A}(0), \mathrm{A}(6)$ & $20 / 100$ & $20 / 32$ & +5 & 27 & $\begin{array}{l}\text { Dry and } \\
\text { quiescent }\end{array}$ & $\begin{array}{l}\text { Resolved PED } \\
\text { and SRF }\end{array}$ & \\
\hline 7/M/58 & Extrafoveal & & $\mathrm{A}(0)$ & $20 / 40$ & $20 / 40$ & 0 & 20 & $\begin{array}{l}\text { Dry and } \\
\text { quiescent }\end{array}$ & Resolved SRF & \\
\hline $8 / \mathrm{M} / 62$ & Subfoveal & $P(-16)$ & $\mathrm{A}(0), \mathrm{A}(6), \mathrm{A}(12)$ & $20 / 50$ & $20 / 32$ & +2 & 13 & $\begin{array}{l}\text { Dry and } \\
\text { quiescent }\end{array}$ & Resolved PED & \\
\hline
\end{tabular}

$\mathrm{M}=$ male; $\mathrm{F}=$ female; $\mathrm{Tx}=$ treatment $\mathrm{F} / \mathrm{U}=$ follow-up; $\mathrm{P}=$ photodynamic therapy, $\mathrm{PDT} ; \mathrm{T} / \mathrm{G}=\mathrm{t}-\mathrm{PA}$ with gas injection; $\mathrm{L}=$ focal laser photocoagulation, $\mathrm{A}=$ intravitreal bevacizumab; $\mathrm{BCVA}=$ best corrected visual acuity; $\mathrm{PED}=$ pigment epithelial detachment; $\mathrm{SRF}=$ subretinal fluid $\mathrm{RPE}=$ retinal pigment epithelium.

* Treatment (time, weeks); ** BCVA before intravitreal bevacizumab; ${ }^{\dagger}$ follow-up duration after intravitreal bevacizumab injection; ${ }^{*}$ Localized bleeding at 6 weeks after PDT plus intravitreal bevacizumab. 
Table 2. Clinical Data and Treatment Results in Patients with Polypoidal Choroidal Vasculopathy Treated by Intravitreal Bevacizumab combined with photodynamic therapy (Group 2)

\begin{tabular}{|c|c|c|c|c|c|c|c|c|c|c|}
\hline $\begin{array}{l}\text { PatientNo./ } \\
\text { Gender/ } \\
\text { Age (years) }\end{array}$ & Location & $\begin{array}{l}\text { Prior } \\
\text { Tx }\end{array}$ & Treatment* & $\begin{array}{l}\text { BCVA } \\
\text { Pre** }\end{array}$ & $\begin{array}{l}\text { BCVA } \\
\text { Final }\end{array}$ & $\begin{array}{l}\text { Change } \\
\text { in lines }\end{array}$ & $\begin{array}{l}\text { Duration } \\
\text { of } F / U^{\dagger} \\
\text { (week) }\end{array}$ & $\begin{array}{l}\text { Clinical and } \\
\text { angiographic } \\
\text { features } \\
\text { at last } \mathrm{F} / \mathrm{U}\end{array}$ & $\begin{array}{l}\text { OCT } \\
\text { features } \\
\text { at last } \mathrm{F} / \mathrm{U}\end{array}$ & $\begin{array}{l}\text { Additional } \\
\text { event }\end{array}$ \\
\hline 9/F/51 & Subfoveal & $\mathrm{P}(-88)$ & $\mathrm{P}+\mathrm{A}(0), \mathrm{A}(6), \mathrm{A}(12)$ & $20 / 250$ & $20 / 250$ & 0 & 13 & $\begin{array}{l}\text { Persistent } \\
\text { serous PED }\end{array}$ & $\begin{array}{l}\text { Persistent } \\
\text { serous PED }\end{array}$ & $\begin{array}{l}\text { Localized } \\
\text { bleeding }(6)^{\ddagger}\end{array}$ \\
\hline $10 / \mathrm{M} / 57$ & Subfoveal & & $\mathrm{P}+\mathrm{A}(0), \mathrm{A}(6), \mathrm{A}(12)$ & $20 / 63$ & $20 / 32$ & +3 & 13 & $\begin{array}{l}\text { Persistent } \\
\text { serous PED }\end{array}$ & $\begin{array}{l}\text { Persistent } \\
\text { serous PED }\end{array}$ & \\
\hline $11 / \mathrm{M} / 45$ & Extrafoveal & $\mathrm{T} / \mathrm{G}$ & $\mathrm{P}+\mathrm{A}(0), \mathrm{L}(4)$ & $20 / 100$ & $20 / 25$ & +6 & 22 & $\begin{array}{l}\text { Dry and } \\
\text { quiescent }\end{array}$ & $\begin{array}{l}\text { Resolved PED } \\
\text { and SRF }\end{array}$ & \\
\hline $12 / \mathrm{M} / 62$ & Subfoveal & & $\mathrm{P}+\mathrm{A}(0), \mathrm{A}(6), \mathrm{A}(12)$ & $20 / 32$ & $20 / 20$ & +2 & 13 & Quiescent & Resolved PED & \\
\hline
\end{tabular}

$\mathrm{M}=$ male; $\mathrm{F}$ =female; $\mathrm{Tx}=$ treatment; $\mathrm{F} / \mathrm{U}=$ follow-up; $\mathrm{P}=$ photodynamic therapy, $\mathrm{PDT} ; \mathrm{T} / \mathrm{G}=\mathrm{t}-\mathrm{PA}$ with gas injection; $\mathrm{A}=$ intravitreal bevacizumab; $\mathrm{BCVA}=$ best corrected visual acuity; $\mathrm{PED}=$ pigment epithelial detachment; $\mathrm{SRF}=$ subretinal fluid;RPE $=$ retinal pigment epithelium.

* Treatment (time, weeks); ** BCVA before intravitreal bevacizumab; ${ }^{\dagger}$ follow-up duration after intravitreal bevacizumab injection; ${ }^{\ddagger}$ Localized bleeding at 6 weeks after PDT plus intravitreal bevacizumab.

respectively). Case 11 in group 2 had received prior gas tamponade with t-PA due to massive submacular hemorrhage at presentation. Case 4 had previously received gas tamponade with t-PA due to massive submacular hemorrhage followed by prior PDT. All patients who had received prior treatment switched treatment to intravitreal injection of bevacizumab with/without combined PDT owing to persistent or recurrent PCV. All patients except cases 5, 7 and 11 received repeated intravitreal bevacizumab at 6 week intervals owing to persistent subretinal fluid, as shown by OCT analysis, or leakage, as shown by FA/ICGA analysis. Intravitreal bevacizumab was well tolerated in all patients. There were no procedure-related complications in any of the patients.

Mean follow-up duration was 17 weeks (range, 12-27) in group 1 and 15 weeks (range, 13-22) in group 2. The mean number of intravitreal bevacizumab injections was 2.2 in group 1 and 2.5 in group 2. Mean BCVA improved in both groups from $20 / 63$ to $20 / 40$ in group 1 and $20 / 63$ to 20/32 in group 2. Of all eyes, BCVA improved by $\geq 2$ lines in seven $(58 \%)$ eyes, and there was a moderate gain in vision in four (33\%) of these eyes (BCVA improved by $\geq 3$ lines). Three $(25 \%)$ eyes had stable vision, with BCVA at the last follow-up being within 1 line of the initial BCVA level. Resolution of fluid and hemorrhages in clinical examination, and absence of leakage on repeat FAs or resolved pigment epithelial detachment (PED) and/or subretinal fluid (SRF) on OCT examinations could be seen in $10(83 \%)$ eyes. Regression of the polypoidal vessels and interconnecting vessels were seen in most cases at the last follow-up.

\section{Case Report (Cases 3 and 4)}

A 63-yearold man was referred to our clinic with a 5 month history of reduced visual acuity in the right eye. At the first visit, his visual acuity was $20 / 63$ in the right eye and 20/20 in the left eye. Based on the findings in FA and
ICGA, he was diagnosed as having PCV in his right eye and was treated with PDT covering whole active lesions. Four weeks after PDT, funduscopic examination of the right eye revealed extensive subretinal hemorrhage with a reduced visual acuity of $20 / 320$. The right eye with massive subretinal hemorrhage was treated with intravitreal $\mathrm{t} P A(50 \mu \mathrm{g})$ and 0.3 $\mathrm{ml}$ of $100 \% \mathrm{C}_{3} \mathrm{~F}_{8}$. Postoperative prone positioning was maintained for 72 hours. Two weeks after administration of t-PA injection and gas, funduscopic examination of the right eye showed dispersed and reduced subretinal hemorrhage (Fig. 1). At one month follow up, he complained a decreased vision to $20 / 50$ in his untreated, left eye. The OCT examination demonstrated subfoveal serous elevation and FA/ICGA confirmed new active PCV in his left eye (Fig. 2). Both eyes were treated with an intravitreal injection of 1.25 $\mathrm{mg}$ bevacizumab, two injections in the right eye and three injections in the left eye, at 6 week intervals. The final visual acuity was $20 / 320$ in the right eye with fibrovascular scarring and 20/32 in the left eye with minimal subfoveal serous elevation.

\section{Discussion}

Polypoidal choroidal vasculopathy (PCV) was first described by Yannuzzi et al. ${ }^{1}$ and is characterized by an abnormal vascular network of choroidal vessels with polyplike dilations at the terminals of the branches. It is unclear whether PCV represents abnormal vessels from the choroidal circulation or is a variant of CNV. However, it is generally considered distinct from $\mathrm{CNV}$ of age-related macular degeneration (AMD) for several reasons. First, PCV mainly affects Asians and pigmented individuals and is associated with an earlier onset and a relatively benign clinical course. 1 Second, a few histopathologic studies have revealed that, unlike CNV which is located mainly under the Bruch's membrane, polypoidal lesions and a branching vascular network are observed inside the Bruch's membrane in cases 


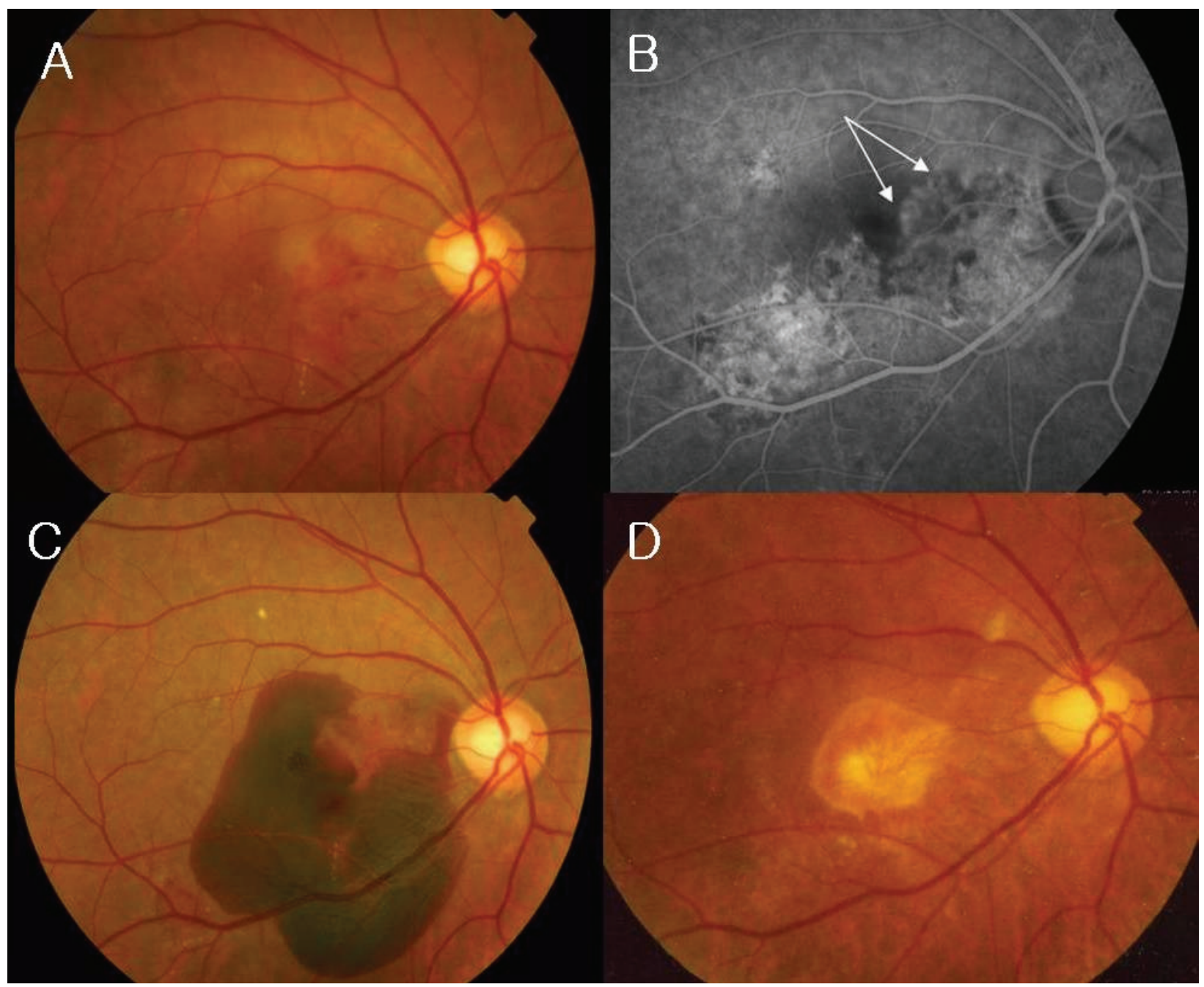

Fig. 1. Case 4, with exudative maculopathy in the right eye. (A) Fundus photograph showing subretinal blood and subretinal serous detachment. (B) Midphase fluorescein angiogram (FA) showing an irregular hyperfluorescent area corresponding to the interconnecting vascular network (arrow). (C) Fundus photograph 4 weeks after photodynamic therapy (PDT) showing a massive subretinal hemorrhage, including the posterior pole. (D) Fundus photograph after two intravitreal bevacizumab injections followed by an intravitreal injection of tissue plasminogen activator $(\mathrm{t}-\mathrm{PA})$ and $100 \% \mathrm{C}_{3} \mathrm{~F}_{8}(0.3 \mathrm{ml})$, showing chorioretinal scarring.

of PCV. ${ }^{11}$ Finally, although eyes affected with PCV have several retinal features in common with $\mathrm{CNV}$ of $\mathrm{AMD}$, they also have some unique features such as a large (greater than 4-disc area) serosanguinous retinopathy, orange polyp-like structures, an absence of macular drusen, and multiple lesions scattered throughout the posterior pole including the peripapillary region. ${ }^{1}$

Since the role of VEGF in the pathogenesis of CNV was established, several studies have reported on the efficacy of anti-VEGF therapy for the treatment of AMDrelated CNV. ${ }^{15}$ 17 An earlier study found that pegaptanib (OSI/Eyetech, Melville, NY) slowed the rate of visual loss, and a more recent, well-controlled study demonstrated a marked improvement in visual acuity following ranibizumab (Genentech, South San Francisco, CA) treatment of exudat ANB AMD patients. ${ }^{22,23}$ Although bevacizumab (Genetech) may have a lower affinity for VEGF than ranibizumab owing to structural differences, it has been reported to be as efficacious as ranibizumab in the treatment of $\mathrm{CNV}$ secondary to AMD or pathologic myopia by several investigators. $^{15-18}$

While the present study has a limitation with its retrospective design, non-randomized treatment groups, a small series of patients, and short follow-up time, our results as a pilot study demonstrate the benefits of intravitreal injection of bevacizumab, either as monotherapy or in combination with PDT, for the treatment of active PCV. This is not surprising considering previous reports demonstrating the role of VEGF in PCV. ${ }^{19,20}$

Although PDT is often considered a standard treatment modality for PCV owing to a high regression rate and favorable functional outcome, it is associated with several disadvantages. ${ }^{12,13}$ First, PCV often presents as multiple, widely distributed lesions, so it might be difficult to treat all 


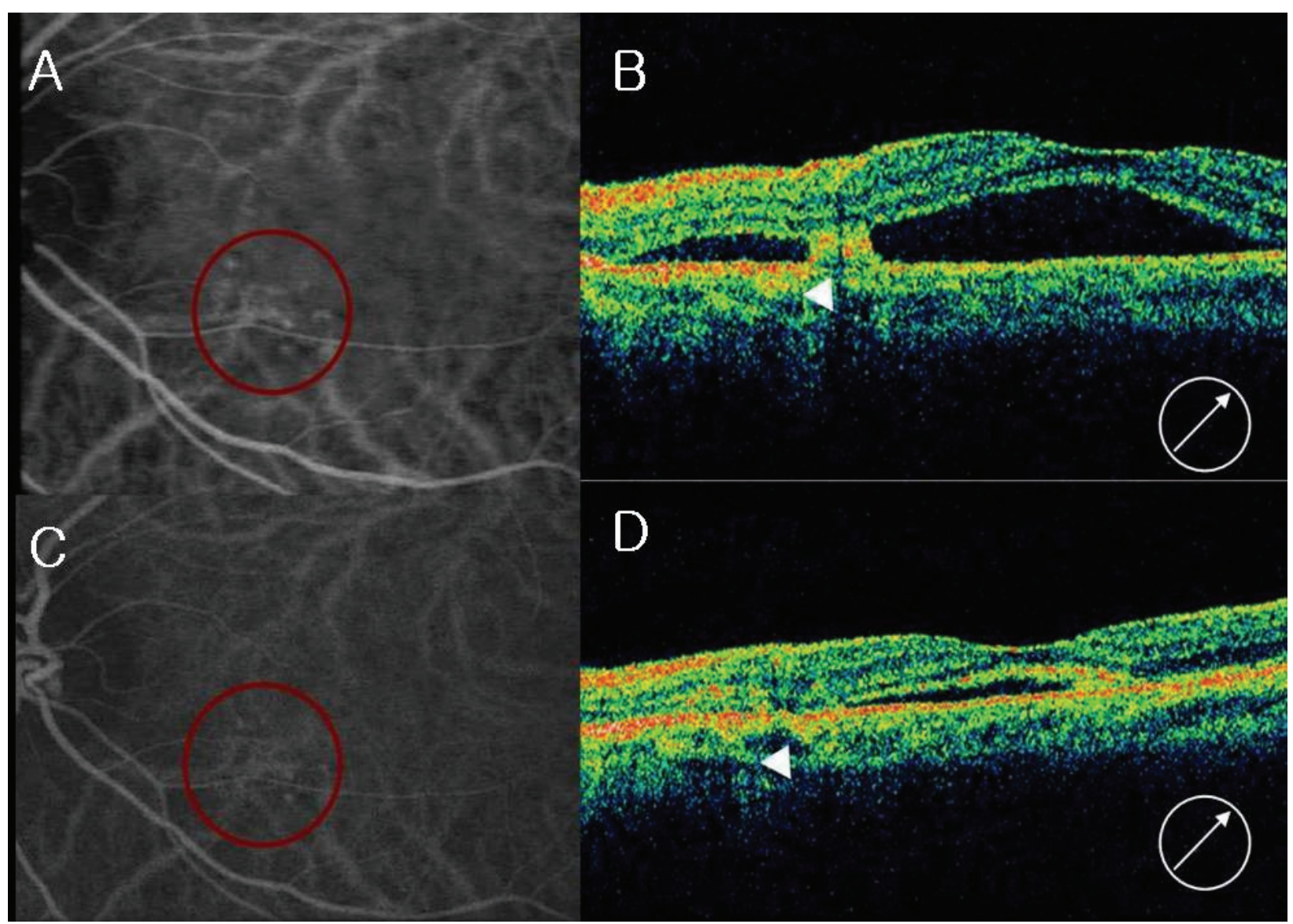

Fig. 2. Case 3, left eye, the fellow eye of the case 4 patient (Fig. 1). (A) Midphase indocyanine green angiogram (ICGA), showing multiple polypoidal dilations of choroidal vessels and an interconnecting network. (B) Optical coherence tomograph (OCT) showing subfoveal serous elevation and a polypoidal lesion (arrow head). (C) Midphase ICGA showing reduced polypoidal lesion and interconnecting vessels. (D) OCT after three intravitreal bevacizumab injections, showing reduced subretinal fluid and a polypoidal lesion re-attached to the Bruch's membrane and choroids (arrow head).

lesions, including multiple polyps and interconnecting vessels, with a single beam of PDT. Treatment of leaking polypoidal dilations only without treating the entire vascular complex can result in persistence or worsening of exudation. ${ }^{24,25}$ Second, it can be difficult to treat nodules in the peripapillary area with a round PDT beam. ${ }^{26}$ Third, features commonly associated with PCV such as a large PED or a large submacular hemorrhage are not usually amenable to PDT treatment. ${ }^{27,28}$ Fourth, PCV tends to recur repeatedly so multiple PDT treatments are often necessary, which can increase the risk of long-term choroidal atrophy. ${ }^{29}$ Finally, cases of massive subretinal/suprachoroidal hemorrhage, as in case 4 in this study, have been reported soon after PDT. ${ }^{14,30,31}$ Although a direct causal association has not been proven, this devastating complication usually results in irreversible visual loss so the risk should be avoided whenever possible.

Although bevacizumab is recommended as adjuvant therapy in combination with PDT for advanced cases that require prompt closure of an abnormal choroidal neovascular complex (Fig. 4), our results indicate that bevacizumab alone may now be considered a primary treatment for early, milder cases, which often occur in the other eye of a patient with an already badly affected eye (Fig. 1, 2). The bilateral example (cases 3 and 4) presented in the case report are examples of a particularly serious complication of PDT, which could be avoided by treatment with bevacizumab alone in the patient's other eye. Longer follow-up is necessary to determine whether repeat bevacizumab injections alone are sufficient to induce permanent regression of PCV, or whether combination therapy with PDT is required.

As the use of intravitreal triamcinolone as an adjunct to PDT has been shown to improve the visual outcome by downregulated expression of inflammatory mediators, and possibly VEGF, after PDT, direct inhibition of VEGF by bevacizumab in combination with PDT may provide a beneficial synergistic effect. ${ }^{32}$ In addition, direct VEGF inhibition with combination treatment would not only reduce the potential for neovascularization, but would also reduce retinal edema owing to laser burn.

This study has several limitations, including retrospective design, non-randomized treatment groups, a small series of patients, and short follow-up time. However, rapid 
improvement in vision as well as no significant complications after intravitreal bevacizumab treatment are encouraging, and may indicate that intravitreal bevacizumab should be considered a new treatment for active symptomatic PCV.

In conclusion, our results indicate that intravitreal bevacizumab treatment, either alone or in combination with PDT, may be a promising approach for treating active, symptomatic PCV. Further investigations including a large, controlled trial, are necessary to determine the efficacy.

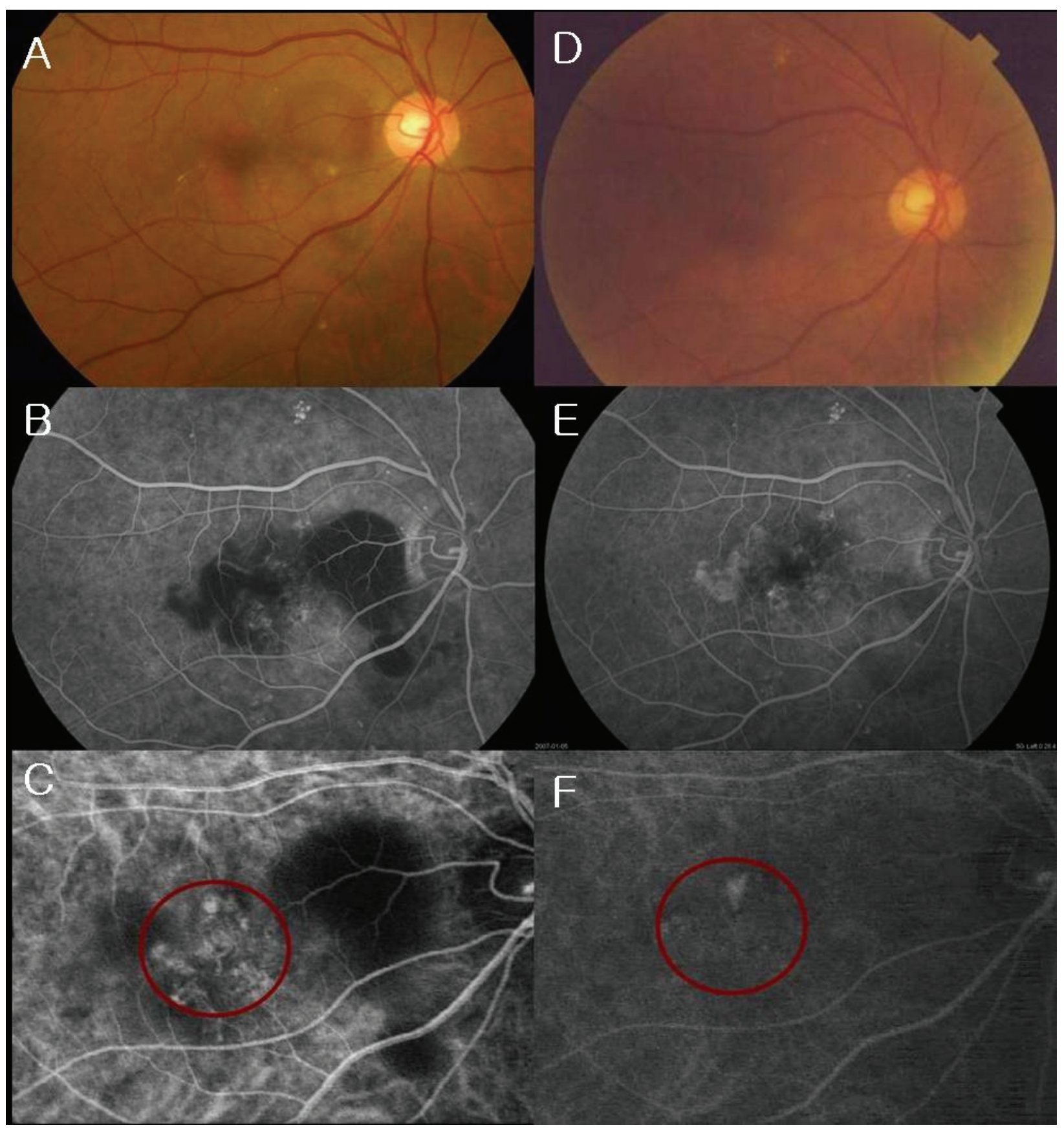

Fig. 3. Case 8 with persistent active polypoidal choroidal vasculopathy (PCV) 4 months after photodynamic therapy (PDT). (A) Fundus photograph showing dense subretinal hemorrhages and serous subretinal detachment. (B) Midphase fluorescein angiogram (FA) showing hypofluorescence corresponding to a subretinal hemorrhage and multiple dot-shaped hyperfluorescent lesions. (C) Midphase indocyanine green angiogram (ICGA) showing multiple polypoidal dilations of choroidal vessels and an interconnecting vascular network. (D) Fundus photograph after three intravitreal bevacizumab injections, showing resolved subretinal hemorrhages and serous subretinal detachment. (E) Midphase FA after three intravitreal bevacizumab injections, showing only the retinal pigment epithelium (RPE) window defect without angiographic leakage in late phase (not shown). (F) Midphase ICGA after three intravitreal bevacizumab injections, showing regression of the polyps and an interconnecting vascular network. 


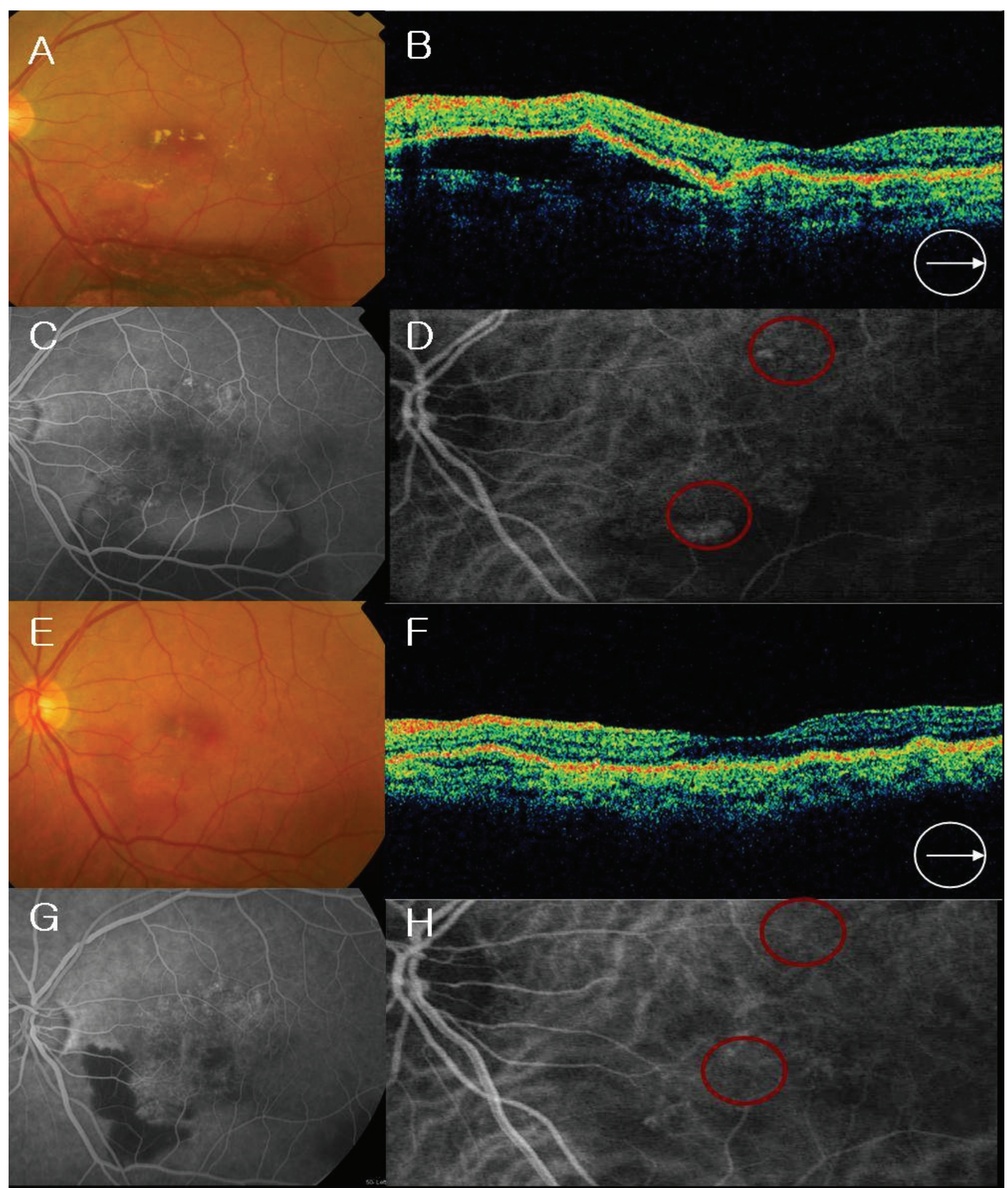

Fig. 4. Case 12 (A) Fundus photograph showing some hemorrhages, subretinal serous detachment, and subretinal exudates. (B) Optical coherence tomograph (OCT) showing serous pigment epithelial detachment (PED). (C) Midphase fluorescein angiogram (FA) showing hyperfluorescence with serous PED and round, multiple isolated hyperfluorescence lesions and surrounding irregular hyperfluorescence. (D) Midphase indocyanine green angiogram (ICGA) showing multiple polypoidal dilation of the choroidal vessels and interconnecting network. (E) Fundus photograph after three intravitreal bevacizumab injections and one round of photodynamic therapy (PDT), showing reduced hemorrhages and subretinal serous elevation. (F) OCT after three intravitreal bevacizumab injections and one round of PDT, showing resolved serous PED. (G) Midphase fluorescein angiogram (FA) after three intravitreal bevacizumab injections and one round of PDT, showing reduced hyperfluorescence and reduced subretinal fluid. (H) Midphase ICGA after three intravitreal bevacizumab injections and one round of PDT, showing resolved polypoidal lesion and interconnecting vessels. 


\section{$\underline{\text { References }}$}

1. Yannuzzi LA, Sorenson J, Spaide RF, et al. Idiopathic polypoidal choroidal vasculopathy (IPCV). Retina 1990;10:1-8.

2. Spaide RF, Yannuzzi LA, Slakter JS, et al. Indocyanine green videoangiography of idiopathic polypoidal choroidal vasculopathy. Retina 1995;15:100-10.

3. Yannuzzi LA, Wong DW, Sforzolini BS, et al. Polypoidal choroidal vasculopathy and neovascularized age-related macular degeneration. Arch Ophthalmol 1999;117: 1503-10.

4. Uyama M, Matsubara T, Fukushima I, et al. Idiopathic polypoidal choroidal vasculopathy in Japanese patients. Arch Ophthalmol 1999;117:1035-42.

5. Moorthy RS, Lyon AT, Rabb MF, et al. Idiopathic polypoidal choroidal vasculopathy of the macula. Ophthalmology 1998;105:1380-5.

6. Yannuzzi LA, Ciardella A, Spaide RF, et al. The expanding clinical spectrum of idiopathic polypoidal choroidal vasculopathy. Arch Ophthal 1997;115:478-85.

7. Uyama M, Wada M, Nagai Y, et al. Polypoidal choroidal vasculopathy: natural history. $\mathrm{Am} J$ Ophthalmol 2002;133:639-48.

8. Yuzawa M, Mori R, Haruyama M. A study of laser photocoagulation for polypoidal choroidal vasculopathy. Jpn J Ophthalmol 2003;47:379-84.

9. Hattenbach LO, Klais C, Koch FH, Gümbel HO. Intravitreous injection of tissue plasminogen activator and gas in the treatment of submacular hemorrhage under various conditions. Ophthalmology 2001;108:1458-92.

10. Shirage F, Matsuo T, Yokoe S, et al. Surgical treatment of submacular hemorrhage associated with idiopathic polypoidal choroidal vasculopathy. Am $J$ Ophthalmol 1999; 128:147-54.

11. Terasaki H, Miyake Y, Suzuki T, et al. Polypoidal choroidal vasculopathy treated with macular translocation: clinical pathological correlation. Br J Ophthalmol 2002;86: 321-7.

12. Spaide RF, Donsoff I, Lam DL, et al. Treatment of polypoidal choroidal vasculopathy with photodynamic therapy. Retina 2002;22:529-35.

13. Chan WM, Lam DS, Lai TY, et al. Photodynamic therapy with verteporfin for symptomatic polypoidal choroidal vasculopathy: one-year results of a prospective case series. Ophthalmology 2004;111:1576-84.

14. Ojima Y, Tsujikawa A, Otani A et al. Recurrent bleeding after photodynamic therapy in polypoidal choroidal vasculopathy. Am J Ophthalmol 2006;141:958-60.

15. Rosenfeld PJ, Moshfeghi AA, Puliafito CA. Optical coherence tomography findings after an intravitreal injection of bevacizumab (Avastin) for neovascular age-related macular degeneration. Ophthalmic Surg Lasers Imaging 2005;36:331-5.

16. Avery RL, Pieramici DJ, Rabena MD, et al. Intravitreal bevacizumab (Avastin) for neovascular age-related macular degeneration. Ophthalmology 2006;113:363-72.

17. Spaide RF, Laud K, Fine HF, et al. Intravitreal bevacizumab treatment of choroidal neovascularization secondary to age-related macular degeneration. Retina
2006;26:383-90.

18. Nguyen QD, Shah S, Tatlipinar S, et al. Bevacizumab suppresses choroidal neovascularizsation caused by pathological myopia. Br J Ophthalmol 2005;89:1368-70.

19. Tong JP, Chan WM, Liu DT, et al. Aqueous humor levels of vascular endothelial growth factor and pigment epithelium-derived factor in polypoidal choroidal vasculopathy and choroidal neovascularization. $A m \mathrm{~J}$ Ophthalmol 2006;141:456-62.

20. Matsuoka M, Ogata N, Otsuji T, et al. Expression of pigment epithelium derived factor and vascular endothelial growth factor in choroidal neovascular membranes and polypoidal choroidal vasculopathy. Br J Ophthalmol. 2004;88: 809-15.

21. Lafaut BA, Aisenbrey S, Van den Broecke C, et al. Polypoidal choroidal vasculopathy pattern in age-related macular degeneration: a clinicopathologic correlation. Retina. 2000;20:650-4.

22. VEGF inhibition study in ocular neovascularization clinical trial group, Chakravarthy U, Adamis AP, Cunningham ET $\mathrm{Jr}$, et al. Year 2 efficacy results of 2 randomized controlled clinical trial of pegaptanib for neovascular age-related macular degeneration. Ophthalmology 2006;113:1508-25.

23. Heier JS, Antoszyk AN, Pavan PR et al. Ranibizumab for treatment of neovascular age-related macular degeneration: a phase I/II multicenter, controlled, multidose study. Ophthalmology 2006;113:642-4.

24. Mauget-Faysse M, Quaranta-El Maftouhi M, De La Marnierre E, Leys A. Photodynamic therapy with verteporfin in the treatment of exudative idiopathic polypoidal choroidal vasculopathy. Eur $J$ Ophthalmol 2006;16:695-704.

25. Lafaut BA, Leys AM, Snyers B, et al. Polypoidal choroidal vasculopathy in Caucasians. Grafes Arch Clin Exp Ophthalmol 2000;238:752-9.

26. Ciardella AP, Donsoff IM, Huang SJ, et al. Polypoidal choroidal vasculopathy. Surv Ophthalmol 2004;49:25-37.

27. Tsujikawa A, Sasahara M, Otani A. et al. Pigment epithelial detachment in polypoidal choroidal vasculopathy. $\mathrm{Am} \mathrm{J}$ Ophthalmol 2007;143:102-11.

28. Sho K, Takahashi K, Yamada H, et al. Polypoidal choroidal vasculopathy: incidence, demographic features, and clinical characteristics. Arch Ophthalmol 2003;121:1392-6.

29. Silva RM, Figueira J, Cachulo ML, et al. Polypoidal choroidal vasculopathy and photodynamic therapy with verteporfin. Grafes Arch Clin Exp Ophthalmol 2005;243: 973-9.

30. Lee SC, Seong YS, Koh HJ, etl al. Photodynamic therapy with verteporfin for polypoidal choroidal vasculopathy of the macula. Ophthalmologica 2004;218:193-201.

31. Chan WM, Liu DT, Lai TY et al. Extensive submacular hemorrhage in polypoidal choroidal vasculopathy managed by sequential gas displacement and photodynamic therapy: a pilot study of one-year follow up. Clin Exp Ophthalmol 2005;33:611-8.

32. Augustin AJ, , Schmidt-Erfurth U. Verteporfin therapy combined with' intravitreal triamcinolone in all types of choroidal neovascularization due to age-related macular degeneration. Ophthalmology 2006;113:14-22. 